\title{
O TRABALHO COM PROJETOS: UMA PROPOSTA INCLUSIVA PARA O ENSINO DE MATEMÁTICA
}

Naiara Chierici da Rocha, Elisa Tomoe Moriya Schlünzen, Danielle Aparecida do Nascimento dos Santos

Universidade Estadual Paulista - FCT/UNESP, Mestrado em Educação, Presidente Prudente, SP. Agência de fomento: CAPES. E-mail: naiaracr27@gmail.com

\section{RESUMO}

O presente trabalho tem por objetivo apresentar reflexões acerca da pedagogia de Projetos para o ensino de Matemática, numa perspectiva inclusiva, a partir do ensino colaborativo entre uma professora da Educação Especial, especialista na área da Deficiência Intelectual (DI) com uma professora de Matemática que atua no 60 ano do ensino fundamental. Será apresentado, um projeto realizado a partir de uma pesquisa de Mestrado em uma escola estadual de Presidente Prudente/SP, onde foi construído de forma colaborativa para o ensino de Matemática em uma sala de aula comum com duas estudantes com DI incluídas. Assim, foi possível pontuar considerações sobre a potencialidade de colaboração e cooperação que a pedagogia de Projetos possibilita no ambiente escolar, propiciando ações em parceria de toda equipe escolar, bem como refletir sobre as necessidades de mudanças e posturas para uma escola inclusiva.

Palavras-chave: Trabalho com Projetos, Ensino colaborativo, Matemática, Inclusão

\section{WORKING WITH PROJECTS: AN INCLUSIVE PROPOSAL FOR MATH EDUCATION}

\begin{abstract}
This study aims to present reflections on the Project Pedagogy for the teaching of mathematics in an inclusive perspective. The main metodology is the Collaborative learning from a teacher of Special Education, expert in Intellectual Disabilities (ID), with a mathematics teacher in the 6th grade of elementary school. Will be presented, a project conducted from a Master's research in a public school in Presidente Prudente/SP, where it was built collaboratively to the teaching of mathematics in an ordinary classroom with two ID students included. It was possible considerate the potential for collaboration and cooperation that Project Pedagogy enables in the school, providing partnership activities of all school staff, as well as reflect about changing necessities towards an inclusive school.
\end{abstract}

Keywords: Project Pedagogy, Collaborative Learning, Mathematics, Inclusion 


\section{INTRODUÇÃO}

Esse trabalho tece reflexões sobre o Trabalho com Projetos para o ensino de Matemática, a partir do ensino colaborativo entre uma professora da Educação Especial, especialista na área da Deficiência Intelectual (DI) com uma professora de Matemática que atua no 6으 ano do ensino fundamental. Será apresentado, um projeto realizado a partir de uma pesquisa de Mestrado em uma escola estadual de Presidente Prudente/SP, onde foi construído colaborativamente para o ensino de Matemática em uma sala de aula comum com duas estudantes com DI incluídas.

A construção de práticas e estratégias de ensino em uma perspectiva colaborativa, segundo Rabelo (2012), amplia o olhar sobre os desafios, auxilia no compartilhamento das dificuldades enfrentadas no processo de inclusão e torna os profissionais mais responsáveis pela escolarização de todos os estudantes. A construção colaborativa entre os profissionais da educação pode favorecer a inclusão escolar dos estudantes Público-Alvo da Educação Especial $(\mathrm{PAEE})^{1}$, e por isso, se faz necessário pensar em metodologias que proporcione práticas e construções colaborativas para um ensino para todos.

Nesse sentido, a proposta de uma pedagogia centrada no trabalho com projetos surge de forma consistente a partir da discussão de John Dewey (1976) sobre as vertentes de uma "Pedagogia Ativa". Já nessa época a discussão centrava-se na concepção de que a "educação é um processo de vida e não uma preparação para a vida futura e a escola deve representar a vida presente - tão real e vital para o aluno como a que ele vive em casa, no bairro ou no pátio" (DEWEY, 1976).

Trabalhar com projetos envolve pareceria, colaboração e cooperação. Segundo Almeida e Fonseca (2000), trabalhar com projetos envolve o aprender fazendo, agindo, experimentando, a partir do modo natural, construindo o conhecimento, possibilitando uma estratégia fundamental da aprendizagem que é o modo de ver do ser humano que aprende.

Na concepção de Boutinet (1990) ao se trabalhar com projetos tem-se a articulação entre duas dimensões, a individual e a coletiva, pois há um reconhecimento social que legitima o projeto, mesmo esse sendo individual. No planejamento e desenvolvimento de um projeto há a criação de espaços colaborativos de ensino e aprendizagem, pois a proposta de se trabalhar com projetos proporciona segundo Santos (2007) uma nova dimensão para sala de aula comum, transformando o tempo, espaço e as relações estabelecidas entre os participantes.

Portanto, o ensino de Matemática a partir da pedagogia de projetos possibilita segundo

\footnotetext{
${ }^{1}$ Consideram-se como estudantes PAEE: Pessoas com Deficiência (Auditiva - DA, Física - DF, Intelectual - DI e Visual - DV), Transtornos Globais do Desenvolvimento (TGD) e Altas Habilidades/Superdotação.
} 
Santos (2007) considerar as diferenças existentes na sala de aula, bem como ritmos de aprendizagem e de experiências de vida, não fragmentando o tempo e o espaço escolar. Com isso, se articular as concepções de um ensino colaborativo nas construções de estratégias pedagógicas pautadas no trabalho com projetos.

\section{METODOLOGIA}

O projeto Gestão Ambiental: Eu no ambiente escolar, foi construído a partir do tema central "gestão ambiental". Essa escolha deu-se por alguns motivos que emergiram do próprio contexto. Primeiramente, foi refletido junto às professoras características da sala de aula, alguns problemas existentes, bem como, necessidades e potencialidades de cada estudante. Em seguida, pensou-se, em parceria, temas que contemplariam o currículo de Matemática, considerando a transversalidade proposta pela pedagogia de Projetos. Sendo assim, o currículo previa o tratamento da informação a partir de gráficos e tabelas, e com isso delimitou-se alguns temas para que os estudantes pudessem escolher o que gostaria de pesquisar e conhecer no ambiente escolar. Em votação, a partir de questões e problemas que os próprios estudantes indagaram em relação ao espaço escolar, tomou-se como escolha o tema central "gestão ambiental".

A realidade escolar do 6ano em que o projeto foi desenvolvido retrata alguns problemas frequentes na maioria das escolas de periferia das cidades brasileiras. A sala se caracterizava por um conjunto de diferenças presentes em seus estudantes como, por exemplo, estudantes com Deficiência Intelectual, estudantes negros e economicamente carentes. Muitos se encontravam em situações de repetência e com dificuldades de aprendizagem, outros mesmo com apenas 11 e 12 anos já não possuíam mais interesse pela escola, e por isso não se sentiam parte, sujeitos do contexto escolar.

Havia casos de muitas ausências, de suspensões e casos particulares de desistência escolar. A indisciplina, desrespeito com os colegas e intolerância à diferença do outro também era uma característica presente no interior da sala de aula. Todos esses fatores contribuíam para dificultar um bom desenvolvimento do ensino e aprendizagem em sala de aula e, por isso, escolheu-se um tema e um projeto em que fosse possível, sem evidenciar esses problemas e diferenças, a realização de um trabalho conjunto, a partir de questões relacionadas ao ambiente escolar possibilitando ou potencializando o pertencimento a um grupo, à própria escola tornando-os sujeitos capazes de aprender e se desenvolver, resolvendo problemas, pesquisando, trabalhando em grupo e construindo o conhecimento que tenha um significado e um sentido especial para cada um. 
Dessa forma, a partir do contexto da sala de aula foi feita a seguinte questão para todos os estudantes "O que vocês gostariam de pesquisar e conhecer sobre a escola? " A partir dessa questão, foi possível delimitar o problema pelo qual todos os envolvidos no projeto deveriam responder: "Como é a gestão de recursos recicláveis e orgânicos na escola, levando em conta a atuação e responsabilidade dos próprios alunos no contexto escolar? "

A partir dessas situações problema iniciou-se o planejamento do projeto. Esse planejamento também ocorreu em parceria na sala de aula com o auxílio dos estudantes, mas foi sistematizado e finalizado em parceria com as professoras envolvidas. Sendo assim, o projeto foi desenvolvido em três etapas, com atividades específicas para cada uma delas.

\section{RESULTADOS}

O projeto consistiu em três etapas. Na Etapa 1: Pesquisa na sala de Informática a sala foi dividia em 3 grupos. Dentro do grupo, cada estudante pesquisou, dialogou e sistematizou o que encontrou sobre o tema de pesquisa. Assim, cada grupo entregou um "relatório" que continham os seguintes aspectos: O que são materiais recicláveis e resíduos orgânicos, e qual o tempo de decomposição desses tipos de materiais. Cada grupo ficou responsável por um item. Após o fim do relatório, cada grupo apresentou os resultados da pesquisa, e com a mediação da professora, que anotou os resultados das pesquisas na lousa, cada grupo completou a pesquisa e anotou os resultados dos colegas. Após o compartilhamento da pesquisa, os grupos de organizaram para confeccionar cartazes para ilustrar com imagens a pesquisa de cada grupo. Ao fim dessa etapa foram escolhidos a partir do que cada grupo coletou os itens que foram pesquisados na escola na próxima atividade.

Na Etapa 2: Pesquisa de Campo: Coleta de dados no ambiente escolar, Os estudantes realizaram uma pesquisa de campo em todo o espaço escolar. Primeiramente a pesquisa direcionou-se para a coordenação, a fim de saber quem eram os responsáveis pela compra do material da escola e pela destinação final dos mesmos. Assim, cada grupo ficou responsável por perguntar sobre os materiais selecionados para a coleta dos dados registrando os dados no caderno de anotações. Itens pesquisados: Grupo dos materiais recicláveis: Quantidade comprada de cada material (que foi selecionado para a pesquisa) e o consumo desses materiais. Grupo dos materiais/resíduos orgânicos: Como é comprada a comida da escola, a quantidade e consumo da mesma. Grupo da reciclagem e decomposição: Pesquisaram sobre a existência de algum processo de reciclagem na escola, e se sim como é feita e controlada a reciclagem. Em relação aos resíduos 
orgânicos esse grupo também pesquisou sobre a quantidade de comida que é armazenada e reutilizada, a quantidade que sobra e qual a destinação dessa sobra.

Na Etapa 3: Organização dos dados e construção de tabelas resultou na sistematização dos dados coletados pelos grupos na pesquisa de campo. Com isso, foi possível explorar de forma satisfatória a construção de tabelas, desde da sua definição, função e estruturação. As tabelas foram construídas a partir dos dados de cada grupo. A construção das tabelas foram: Tabela 1: Organização do Lixo na escola; Tabela 2: Quanto tempo dura o nosso lixo; Tabela 3: Consumo de alguns materiais recicláveis na escola; Tabela 4: Consumo de comida na merenda escolar.

Após a construção das etapas do projeto foi o momento da sistematização dos conceitos com a professora de Matemática, assim como para complementar a sistematização a professora especialista em DI também sistematizou alguns conceitos com as estudantes com DI.

A sistematização partiu-se do que os estudantes construíram desde a pesquisa até a construção de tabelas para alguns conceitos escolares em relação ao tratamento da informação, como, por exemplo, a leitura e interpretação de tabelas, a organização, estrutura, título de uma tabela e grandezas, assim como, transpor uma tabela para um gráfico. Sendo assim, a possibilidade de se trabalhar com esse projeto partiu do que os estudantes já sabiam, cada um à sua maneira, para a sistematização dos conceitos curriculares.

\section{DISCUSSÃO}

Os resultados obtidos com o desenvolvimento do projeto estão em fase de análise para a escrita da dissertação de Mestrado pelo qual esse projeto se desenvolveu. Mas, é possível já considerar alguns pontos de extrema relevância para o debate no que tange a pedagogia de projetos e o ensino colaborativo.

No que diz respeito ao trabalho com projetos destaca-se que é uma pedagogia consistente, mas uma metodologia, ou estratégias de ensino que os professores em sua maioria não estão preparados para trabalhar. Notou-se o desconhecimento inicial sobre essa pedagogia por parte da professora de Matemática, bem como a surpresa em constatar o que deu certo e que a mudança e efetivação de novas práticas são possíveis, a partir de conhecer e participar de uma proposta como essa.

Notou-se um potencial colaborativo ao se trabalhar com projetos, uma vez que no decorrer do planejamento e execução do projeto contou-se com a parceria da professora de Ciências, em que cedeu algumas explicações e sugestões sobre o Projeto. Esse destaque, enfoca para a questão da cooperação e colaboração que surgiu de forma espontânea. O mesmo ocorreu com toda a 
equipe escolar, desde da coordenação, secretaria, funcionários da limpeza e da cozinha.Com isso, nota-se uma cooperação espontânea no decorrer do planejamento do projeto.

Foi notório a participação e envolvimento das professoras, e dos funcionários da escola. Foram estabelecidos parcerias e cooperação a partir do desenvolvimento do projeto, uma vez que, colaboraram com ele profissionais que não sabiam do planejamento do mesmo. Com isso, a experiência do novo, a carência do envolvimento, a fragmentação do espaço e do tempo em que a escola se configura hoje, demonstra que trabalhar com projetos é uma maneira possível para romper essas barreiras, mas desde que haja estruturas para isso. É necessário repensar as práticas de ensino, mas é também necessário repensar as estruturas e o sistema pelo qual o ensino está organizado.

As práticas colaborativas foram construídas e desenvolvidas, mas foi possível perceber que isso ocorreu muito pelo fato de estar ocorrendo uma na escola, ou seja, percebeu-se maior colaboração para com a pesquisadora do que entre as próprias professoras. Esse fato pode ser atrelado à falta de tempo para um planejamento que propicie parcerias, a falta de formação que dê atribuições e orientações mais consistentes entre os professores sobre o ensino colaborativo e melhores condições de trabalho à equipe escolar, desde a fragmentação das aulas, número de alunos por sala de aula e condições de trabalho dos professores.

\section{CONCLUSÃO}

Conclui-se que, em termos de aprendizagem, pode-se considerar que houve aprendizagens, houve, interação, compartilhamento e construções significativas de conhecimento, isso foi notório a partir dos resultados construídos em cada etapa do projeto, desde de atitudes à sistematização de conceitos. Mas, não se pode dizer que com esse projeto houve mudanças de conduta, tanto na postura dos estudantes quanto nas práticas das professoras, no entanto, pode se refletir que esse foi um passo de investigação que tem possibilitado apresentar fragilidades existentes na escola, mas, ao mesmo tempo, potencialidades de que a mudança é possível.

Em relação às estudantes com DI, pode-se dizer que apenas uma obteve participação total no projeto, participando, compartilhando, e desenvolvendo suas tarefas a partir do seu tempo e da sua maneira, mas concluindo as mesmas tarefas que os demais estudantes, aprendendo um mesmo currículo e pertencendo ao grupo. A outra estudante, por motivos pessoais faltou em quase todas as etapas do projeto, e sendo assim, não foi possível analisar avanços e inclusão dessa estudante. 
Portanto, considera-se que o desenvolvimento de estratégias e práticas de ensino em parcerias, colaboração e cooperação, articulando os serviços da Educação Especial com a escola regular, baseadas na pedagogia de projetos se torna uma possibilidade de um ensino inclusivo, seja para a Matemática, assim como, para todas as áreas do conhecimento. Nesse sentido, acredita-se em metodologias ativas que proporcione práticas de ensino que considere as habilidades dos estudantes ao invés das dificuldades, dado que o ensino é coletivo, mas a aprendizagem é individual e possui um sentido e significado diferente para cada um.

\section{REFERÊNCIAS}

ALMEIDA, F.; FONSECA, F.M.Jr. Projetos e Ambientes Inovadores. Brasília: Ministério da Educação/MEC, 2000.

BOUTINET, J.P. Antropologia do Projecto. Lisboa, Instituto Piaget, 1990.

DEWEY, J. Experiência e educação. 2. ed., São Paulo: Nacional, 1976.

RABELO, L. C. C. Ensino Colaborativo como estratégia de formação continuada de professores para favorecer a inclusão escolar. 2012. 200f. Dissertação (Mestrado em Educação Especial). Universidade Federal de São Carlos. UFSCar. São Carlos, 2012.

SANTOS, D. A. N. A Formação de Professores de uma Escola da Rede Pública Estadual em Serviço para o Trabalho com Projetos Utilizando as Tecnologias de Informação e Comunicação. Presidente Prudente, 2006. Dissertação (Mestrado em Educação). Universidade Estadual Julio de Mesquita Filho, Faculdade de Ciências e Tecnologia, (FCT/UNESP). 